\title{
Assessment of Efficiency of Antianemic Therapy in Pregnant Women Suffering from Anemia
}

\author{
Sattarova K. A. ${ }^{1}$, Jabbarova J. K. ${ }^{2}$, Abdullaev B. Sh. ${ }^{3}$, Makhamedjonova D. F. ${ }^{4}$ \\ ${ }^{1,2}$ Department of Gynecology and Obstetrics (4-5 years students), Tashkent Medical Academy, Tashkent, Uzbekistan \\ ${ }^{3,4}$ Junior scientific researcher, GP faculty, Tashkent Medical Academy, Tashkent, Uzbekistan
}

\begin{abstract}
Nowadays iron-states are a nationwide problem of health care systems in different countries, most often occurring among pregnant women and in early childhood. Iron supplements play leading role in the treatment of this pathology, and for decades of practical application, they have undergone a number of changes. Research efforts are aimed to increase their therapeutic efficiency and reduce the number and severity of side effects. The most modern group of antianemic drugs are non-ionic iron preparations, which represented by Ferrofer. The article discusses the advantages of treatment with combined Ferro therapy with REPO and over using only iron supplement, namely, high efficiency, rapid achievement of the effect, safety, the presence of various forms of release. These features allow to recommend Combination of Ferro and REPO therapy as the primary therapy of iron deficiency anemia in a broad range of patients, including pregnant women, and its effective use in anemia of various severity.
\end{abstract}

Keywords: anemia, Ferrofer, REPO, pregnancy, iron state

\section{Introduction}

Anemia in pregnant women is one of the most urgent health problems in the field of maternal and child health. According to the World Health Organization (WHO), anemia is detected on average in $48 \%$ of pregnant women yearly in the world.

In Central Asia iron deficiency anemia (IDA) is classified as a regional pathology considering its frequent detection among almost all segments of the population, especially in so-called high-risk groups, which include children, adolescents, women of childbearing age, especially pregnant and breastfeeding. IDA is the problem of man, the family, the nation and its power and economy, as well as the future of the population and human resources capacity. The prevalence of iron deficiency anemia in Uzbekistan among pregnant women and women of reproductive age reaches $60-$ $90 \%$, and among the dead mothers - 97-98\%. In Central Asia, this extragenital pathology has been thoroughly studied for over 50 years $[1,2,3]$.

Anemia is one of the most frequently encountered extragenital complications of gestational period of maternal mortality. Anemia is a concomitant of the dead women in almost $100 \%$ of cases. Over the past 18 years in the Republic of Uzbekistan, moderate and severe anemia occurs more often over the years in pregnant women [102.81]. According to World Health Organization (WHO), the frequency of IDA during pregnancy in different countries range from 21 to $80 \%$. In our country, the incidence of anemia among pregnant women reaches 95-97\% [4]. Despite the abundance of works devoted to this problem, the questions of pathogenesis and treatment of anemia in pregnancy are still unresolved in our region; iron deficiency anemia is the most common form of anemia among extragenital diseases in pregnant women, and it ranks the first place and occurs in $60-90 \%$ of patients $[5,6]$.
With increasing severity of anemia, the risk of death in infants and children from infectious diseases increases, mental and cognitive development of the child is disrupted, physical activity and capacity for work of adults is reduced. [7].

\section{Materials and Methods}

We observed and surveyed 93 pregnant women with anemia, aged 16-45 $(21 \pm 0.1)$, who were registered at antenatal clinics and treated in the Department of Pregnancy Pathology of Obstetric Complex №9 in Tashkent.

The criteria for selection of pregnant women into the group were hemoglobin content of $95 \mathrm{~g} / 1$ or less, serum iron 15 $\mathrm{mmol} / 1$ and lower, gestational age - 20 weeks or more, and the absence of other blood diseases.

The contingent of pregnant women was subjected to thorough clinical and laboratory survey. The clinical examination included the study of complaints, life, obstetric and gynecological history, taking into account past diseases and diseases during the pregnancy. There was a general and a special obstetrical examination: external palpation, auscultation of fetus, examination with mirrors at the prenatal rupture of membranes and the outpouring of water, vaginal examination, and examination of the degree of cervical dilatation. A general analysis of blood, urine, secretions from the cervix, vagina, and urethra was carried out in pregnant women. The group and $\mathrm{Rh}$ affiliation of blood, a blood test for HBsAg, RW, with the consent of women to HIV / AIDS were identified.

Also some biochemical indices of peripheral blood were measured: total protein, ALT, AST, coagulation. According to testimony samples of Zimnitsky, Nechiporenko were carried out, electrocardiogram was held. The localization of the placenta and fetal size was determined by ultrasound. All pregnant women consulted with a therapist. 


\section{International Journal of Science and Research (IJSR) \\ ISSN (Online): 2319-7064 \\ Index Copernicus Value (2013): 6.14 | Impact Factor (2014): 5.611}

Depending on the type of antianemic therapy, patients were divided into 2 groups. The comparison group - 63 pregnant women who received Ferrofer $5 \mathrm{ml} / \mathrm{m}$ daily for 5 days; the main group - 30 pregnant women who received Ferrofer $5 \mathrm{ml}$ / $\mathrm{m}$ daily for 5 days and REPO 2000 IU subcutaneously 2-3 injections, depending on the severity of the anemia after 3 days.

\section{Results and Discussion}

Women of the compared groups were mostly in the age range of $21-30 \quad(40 \%)$, characterized as an active reproductive age. Young women and women of late reproductive age were in minimum quantity in all groups except pregnant women of the main group where the number of young pregnant women was $23.8 \%$, and of late age $3.2 \%$. Among them, the number of women in II and III trimesters: $20-27$ weeks - 20 (21.4\%), 28-32 weeks - 35 $(34.3 \%)$ and $33-36$ weeks - 28 (44.3\%), respectively. Primigravidas were $25(30.1 \%)$. Women who were pregnant again were $58(69.9 \%)$, among them in their second pregnancy - $33(39.8 \%)$, in third pregnancy - $16(19.3 \%)$ in fourth or more pregnancies - 9 (10.8\%).

Among surveyed there was a prevalence in women who were pregnant again and multiparous women with a second or third pregnancy, which did not differ in significantly meaningful limits.

In obstetric history there were women with: medical abortion - 13 women (15.6\%), spontaneous abortion - 8 women $(9.6 \%)$, not growing pregnancy - 4 women (4.8), antenatal death of fetus - 3 (3 6).

$24(38.1 \%)$ pregnant women out of 63 from Group 1 started taking Ferrofer in terms of 20-27 weeks of pregnancy, 39 $(61.9 \%)$ - after 28 weeks. In Group 2, treatment of pregnant women was carried out after 28 weeks. The average duration of treatment in Group 1 was $12,4 \pm 2,1$ days and in the Group $2-14 \pm 3,3$ days $(\mathrm{P}<0.05)$. A comparative analysis of the characteristics of menstrual function, past gynecological and extragenital diseases revealed no significant differences between the groups. Pregnant women of both groups equally often met early toxicosis and the threat of termination of pregnancy.

One of the components involved in the regulation of OTC is hematic. Dynamics of red blood cells and serum iron in pregnant women of the Group 1 during treatment with Ferrofer is shown in Table. 3.1, the changes of the same indices in pregnant women of the Group 2 who received the combined treatment of REPO and Ferrofer - Table. 3.2.

As can be seen from Table 3.1 and Table 3.2, at the end of treatment patients of the Group 1 had a significant increase in hemoglobin compared to baseline $(p<0.05)$. At the same time, by the end of the treatment pregnant women from the group 2 had had a significant increase not only in the concentration of hemoglobin, but in the quantity of the red blood cells and hematocrit compared to baseline data ( $p$ $<0.01)$.

Table 3.1: Dynamics of indicators of red blood cells and serum iron in pregnant women with anemia treated with

Ferrofer $(\mathrm{M} \pm \mathrm{m})$

\begin{tabular}{|c|c|c|c|c|c|c|}
\hline \multirow{3}{*}{ Indicator } & \multicolumn{6}{|c|}{ Gestational age } \\
\hline & \multicolumn{2}{|c|}{$20-27$ weeks $n=24$} & \multicolumn{2}{|c|}{$28-32$ weeks $n=24$} & \multicolumn{2}{|c|}{$33-36$ weeks $n=15$} \\
\hline & Before treatment & After treatment & Before treatment & After treatment & Before treatment & After treatment \\
\hline $\mathrm{Hb}, \mathrm{g} / \mathrm{l}$ & $101,3 \pm 1,5$ & $103,1 \pm 2,0$ & $97,7 \pm 3,3$ & $105,7 \pm 2,4^{*}$ & $88 \pm 2,5$ & $110,1 \pm 2,3^{*}$ \\
\hline eryt. $\times 10^{12} / 1$ & $3,4 \pm 0,9$ & $3,5 \pm 0,13$ & $3,4 \pm 0,1$ & $3,5 \pm 0,1$ & $3,3 \pm 0,14$ & $3,4 \pm 0,1$ \\
\hline $\mathrm{Ht}, \%$ & $32 \pm 0,5$ & $32 \pm 0,1$ & $30 \pm 0,3$ & $31 \pm 0,5$ & $30 \pm 0,7$ & $31 \pm 0,3$ \\
\hline Serum iron, micromol / 1 & $13,3 \pm 1,2$ & $15,4 \pm 2,3$ & $12,5 \pm 1,7$ & $14,2 \pm 2,3$ & $12,5 \pm 3,1$ & $16,5 \pm 2,2$ \\
\hline Reticulocytes, \% & $1,3 \pm 0,05$ & $1,1 \pm 0,05$ & $1.4 \pm 0,1$ & $1.2 \pm 0,2$ & $1,3 \pm 0,1^{*}$ & $1,2 \pm 0,1^{*}$ \\
\hline
\end{tabular}

Note. * - P<0.05

Table 3.2: Dynamics of indicators of red blood cells and serum iron in pregnant women with anemia treated with Ferrofer and REPO $(\mathrm{M} \pm \mathrm{m})$

\begin{tabular}{|c|c|c|c|c|}
\hline \multirow{2}{*}{ Indicator } & \multicolumn{3}{|c|}{ Gestational age } \\
\cline { 2 - 5 } & \multicolumn{2}{|c|}{28 -32 weeks $\mathrm{n}=20$} & \multicolumn{2}{c|}{33 -36 weeks $\mathrm{n}=10$} \\
\cline { 2 - 5 } & Before treatment & After treatment & Before treatment & After treatment \\
\hline $\mathrm{Hb}, \mathrm{g} / 1$ & $86 \pm 2,3$ & $118,7 \pm 2,5^{*}$ & $82 \pm 2,0$ & $112,7 \pm 2,6$ \\
\hline eryt. $\times 10^{12} / 1$ & $3,3 \pm 0,14$ & $3,4 \pm 0,1$ & $3,3 \pm 0,14$ & $3,4 \pm 0,1$ \\
\hline $\mathrm{Ht}, \%$ & $30 \pm 0,7$ & $31 \pm 0,3$ & $30 \pm 0,7$ & $31 \pm 0,3$ \\
\hline Serum iron, micromol / & $12,5 \pm 3,1$ & $16,5 \pm 2,2$ & $12,5 \pm 3,1$ & $16,5 \pm 2,2$ \\
\hline Reticulocytes, \% & $1,3 \pm 0,1^{*}$ & $1,2 \pm 0,1^{*}$ & $1,3 \pm 0,1^{*}$ & $1,2 \pm 0,1^{*}$ \\
\hline
\end{tabular}

Note. $* \mathrm{p}<0.05 ; * * \mathrm{P}<0.01$.

\section{Conclusions}

1) Treatment of IDA with only iron containing medications is not sufficiently effective. The level of $\mathrm{Hb}<90 \mathrm{~g} / \mathrm{L}$ and a resistance of anemia to the treatment with Fe drugs is an indication for the REPO therapy, especially during preparation for delivery.

2) Combined Ferro therapy with REPO is an effective and relatively rapid method of IDA relief for pregnant women, which allows a replacement of blood transfusion. 


\section{International Journal of Science and Research (IJSR) \\ ISSN (Online): 2319-7064}

Index Copernicus Value (2013): 6.14 | Impact Factor (2014): 5.611

\section{Acknowledgements}

We thank junior scientific researcher BekhzodAbdullaev for excellent technicaland mentalassistance. Thisstudy was supported byObstetric Complex №9 in Tashkent,Republic ofUzbekistan.

\section{References}

[1] Bermejo F, Garcia-Lo'pez S. A guide to diagnosis of iron deficiency and iron deficiency anemia in digestive diseases. World JGastroenterol. 2009;15:4638-4643.

[2] Ho CH, Chau WK, Hsu HC, Gau JP, You JY, Chen CC. Predictive risk factors and prevalence of malignancy in patients with iron deficiency anemia in Taiwan. Am J Hematol. 2005;78:108-112.

[3] Scholl TO. Iron status during pregnancy: setting the stage for mother and infant. Am J Clin Nutr. 2005;81:1218S$1222 \mathrm{~S}$.

[4] Puolakka J, Janne O, Pakarinen A, Vihko R. Serum ferritin as a measure of stores during and after normal pregnancy with and without iron supplements. Acta Obstet Gynecol Scand 1980;95(suppl):43-51.

[5] World Health Organization. Nutritional anaemias. World Health Organ Tech Rep Ser 1968;405.

[6] Scholl TO, Hediger ML, Fischer RL, Shearer JW. Anemia vs iron deficiency: increased risk of preterm delivery in a prospective study. Am J Clin Nutr 1992;55:985-8.

[7] Rusia U., Madan N., Agarwal N., Sikka M., Sood S. Effect of maternal iron deficiency anaemia on foetal outcome. Indian J Pathol Microbiol 1995;38:273-9. 